\title{
Maximizing Sustainability of Ecosystem Model through Socio-Economic Policies Derived from Multivariable Optimal Control Theory
}

\author{
Rohan Doshi $^{1,3}$, Urmila Diwekar ${ }^{2,3}$, Pahola T. Benavides ${ }^{2,3}$, Kirti M. Yenkie ${ }^{2,3}$, Heriberto Cabezas ${ }^{4,5}$ \\ ${ }^{1}$ Princeton University, Princeton, NJ 08544 \\ ${ }^{2}$ Department of Bioengineering, University of Illinois, Chicago, IL 60607 \\ ${ }^{3}$ Center for Uncertain Systems: Tools for Optimization \& Management (CUSTOM), \\ Vishwamitra Research Institute, Clarendon Hills, IL 60514. \\ ${ }^{4}$ National Risk Management Research Laboratory, Office of Research and Development, U.S. \\ Environmental Protection Agency, Cincinnati, OH 45268 \\ ${ }^{5}$ Department of Computer Science and Systems Technology, University of Pannonia, H-8200 Veszprem, \\ Hungary
}

\begin{abstract}
Current practices in natural resources consumption are unsustainable and may eventually lead to ecosystem extinction. Sustainable ecosystem management is necessary to ensure that human and ecological needs of the present are satisfied without compromising the ability of future generations to meet their own. This paper uses a simple mathematical model of an integrated ecological and economic system representing our planet's sectors, including, but not limited to, natural, industrial, housing, and energy production sectors. The aim of the project is to maximize the sustainability of this system, using Fisher Information as a statistical measure as a measure of sustainability, and derive socio-economic policies using optimal control techniques. By controlling six policy parameters, we were able to sustain all the ecological mass compartments (which were not sustainable in the consumption increase scenario of the future), thus significantly increasing the lifespan of all the species in the model.
\end{abstract}


Keywords: Sustainability, Ecosystem Management, Optimal Control, Policy, Fisher Information, Multivariable

\section{Introduction}

Due to the recent globalization, the average standard of living of the human population has improved considerably. Apart from the conventional primary needs of food, energy, clothing, and shelter, many more commodities have become essential for a stable existence. Consequently, the average per capita consumption of natural resources is rising to unprecedented levels which the environment cannot provide for indefinitely. In fact, researchers have predicted that consumption of many resources will increase by about $50 \%$ in the next 50 years (Meadows et al. 1992). The intensification of human activities and its continuous evolution has encouraged different sectors of society to explore alternatives that counteract the negative impact of human development. Therefore, sustainability has emerged as a new discipline for analysis and evaluation that has different dimensions corresponding to political, social and economic sectors in relation to human activity. When the time dimension is added to sustainability, it becomes more similar to sustainable development, which has been defined as "the development that meets the needs of the present without compromising the ability of future generations to meet their own needs" (Brundtland 1987).

Mathematical models featuring key components of an ecosystem help in the study of sustainable development. These models yield qualitative and quantitative conclusions that aid 
policy makers evaluate technologies and ecosystem management strategies. Often times, these models focus on specific aspects of the environment. For example, Menshutkin et al. (2014) analyze the variety of mathematical models used to understand freshwater lake ecosystems, ranging from those formulated with systems of differential equations to those implemented using fuzzy logic. Chang et al. (2014) mathematically modeled greenhouse gas emissions from Fortune 500 companies to study their impact on the environment and derive policy conclusions. And, Llibre and Xiao (2014) study the global dynamics of a 3-dimensional Lotka-Volterra system, a mathematical representation of predator-prey population dynamics. Of particular interest, the literature features many attempts to incorporate optimal control - the development of time-dependent management strategies - with different ecological models; examples include maximizing forest carbon sequestration, sustaining shallow lake environments, and optimally harvesting fish populations (Sohngen and Mendelsohn 2003; Mäler et al. 2003; Chakraborty et al. 2011). Although all these studies can help us understand and manage specific aspects of our environment, a more comprehensive model of the planet's environment - including both human and natural aspects - is required to evaluate government policy effects across the many aspects of sustainable development. To fill this need, many research projects in the field of sustainability have aimed to incorporate economic features into ecological models to reflect human interactions with nature. Brock and Xepapadeas (2010) incorporated a basic economic-ecological system in their mathematical study of the management and regulation of semi-arid systems. Expanding the scope even more, Whitmore et al. (2006) incorporated a rudimentary economy into a twelve-cell ecological model. Kotecha et al. (2012) further enhanced Whitmore's model by incorporating 
biofuels to depict how energy production impacts sustainability. The Whitmore model has shown that in the current state of our planet, if per capita consumption increases as predicted, our planet will not be sustainable and species will start disappearing. Building upon Whitmore's and Kotecha's framework, we propose a novel application of multivariable optimal control for an integrated model of the planet to derive socio-economic policies in order to sustain the system. Since the government needs to anticipate how the ecosystem will react to not one but an entire array of policy options, we aim to look at multiple policy options which will be controlled simultaneously over time to guide the sustainable development of the system.

Sustainable development reaches across multiple disciplinary considerations; therefore, an equally interdisciplinary theory is required for measuring model sustainability. Previous literature has suggested Fisher Information (FI), a concept from information theory, be used to construct a basic theory of sustainability for ecological applications (Cabezas and Fath 2002). According to Frieden (1998), FI is a measure of the state of order or organization of a system. In a dynamically sustainable regime, the FI remains constant over time or oscillating about a constant value. If the FI is increasing over time, the system is migrating towards a state of increasing self-organization and is in a potentially sustainable state. But if FI is decreasing, the system's loss of organization indicates that it is unsustainable or transitioning to a different regime (Cabezas and Fath 2002). Shastri and Diwekar (2006) presented a mathematical definition of the sustainability hypothesis proposed by Cabezas and Fath (2002) based on FI. They assumed a system with $n$ species, and calculated the time average $\mathrm{FI}_{\mathrm{t}}$ using Equation 1 . 


$$
\begin{aligned}
& F I_{t}=\frac{1}{T_{c}} \int_{0}^{T_{c}} \frac{a(t)^{2}}{v(t)^{4}} d t \\
& v(t)=\sqrt{\sum_{i=1}^{n}\left(\frac{d x_{i}}{d t}\right)^{2}} \quad(\mathrm{i}=1,2 \ldots \mathrm{n}) \\
& a(t)=\frac{1}{v(t)}\left[\sum_{i=1}^{n} \frac{d x_{i}}{d t} \frac{d^{2} x_{i}}{d t^{2}}\right] \quad(\mathrm{i}=1,2 \ldots \mathrm{n})
\end{aligned}
$$

In Equation 1, $\mathrm{T}_{\mathrm{c}}$ is the time cycle, $v(t)$ and $a(t)$ are the velocity and acceleration terms,

defined by Equation 2 and Equation 3 respectively. Here, the terms $\frac{d x_{i}}{d t}$ and $\frac{d^{2} x_{i}}{d t^{2}}$ represent changes found in the $\mathrm{n}$ state variables. In this work, we use an optimal control strategy to regulate the system's FI in order to achieve sustainability. The results presented here yield quantitative and qualitative conclusions about how different combinations of controlled economic, regulatory, and technological policy options can influence individual aspects of the environment as well as the overall ecosystem.

\section{Materials and Methods}

\section{$\underline{2.1 \text { Model Description and Sensitivity Analysis }}$}

The model used for this work is a simplified natural ecosystem compounded with human interactions. The model is broken down into mass compartments, which are allowed for the tracking of mass transfers. Figure 1 gives an overall sense of all interactions occurring between the mass compartments. Refer to Online Resource Section 1 for more details on the model. 


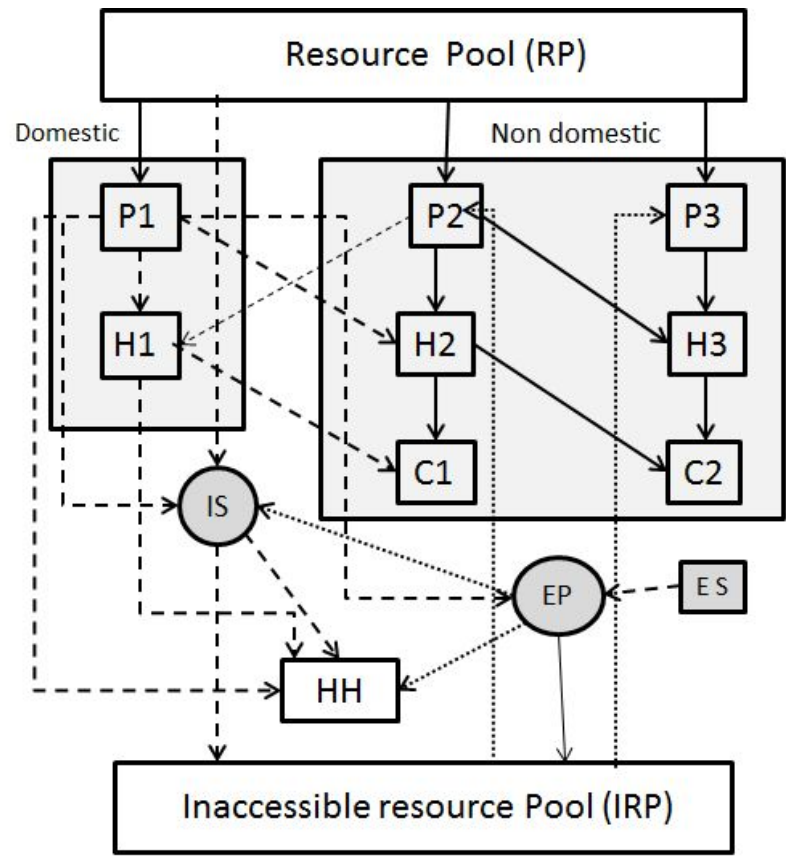

Fig. 1 Compartment of the economic-ecological model. This figure depicts the compartment model, which is comprised of : plants $\left(\mathrm{P}_{\mathrm{i}}\right)$ which are the primary producers, herbivores $\left(\mathrm{H}_{\mathrm{i}}\right)$, carnivores $\left(\mathrm{C}_{\mathrm{i}}\right)$, humans households $(\mathrm{HH})$, a resource pool and inaccessible resource pool (RP, IRP). The arrows represent the mass flows from one compartment (origination) to another compartment (termination), and all living compartments have an implied flow back to the resource pool that represents death. (IS) is the industrial sector, whereas (EP) and (ES) are the energy producers and the energy source compartment, respectively (Kotecha et al. 2012).

The dynamic interactions were formulated based on the Lotka-Volterra (LV) model. Usually these models are represented as differential equations, but the previous work, which formed the basis for this study, altered the LV model to be implemented through difference equations. Since the model presented here is an integrated economic-ecological model, the demand for mass from each compartment depends on a series of economic price equations. Both economic equations and ecological equations are governed by key coefficients. These coefficients address the efficiency of mass transfer and can be manipulated to decelerate or accelerate trends in the model over time. Therefore, altering parameters will impact the model's FI, and, thus, the sustainability. The model also relies on two key assumptions: 
- This model is closed to mass but open to energy.

- Biofuels utilize mass from primary producers for meeting $30 \%$ of the human and industrial energy demand. The biofuel share of energy production is set to $30 \%$ to model the upper bound of biofuel energy production estimates for the future. Remaining energy needs are satisfied by conventional, finite fuel sources such as fossil fuels (Kotecha et al. 2012).

Additionally, the model is simulated for a time-span of two hundred years and can optionally be run with either the following scenarios:

- Base Case (BC): this represents a sustainable system that avoids extinction. The parameter values remain constant and there is no increase in consumption. The base case can serve as a standard for comparison since it can yield information about the dynamics of an ideal system.

- Consumption Increase (CI): certain coefficients related to economic demands for natural resources are increased as expected in the future. This causes many mass compartments to deviate from the $\mathrm{BC}$ and accelerate towards extinction, thus resulting in an unsustainable system.

In terms of implementation, the current model has been solved in Matlab. Kotecha et al. (2012) contains more details about this model. We included additional functions for performing optimal control in order to answer the guiding questions behind this work.

The model presented in this paper was also studied by Benavides et al. (2014). In this work, the model was represented as a network whose properties can be used to determine the 
controllability of the system. The controllability was determined as the minimum number of nodes that can guide the dynamics of the complete system. In that sense, they found that at minimum twelve nodes were needed to completely control the system; they argued that if the system is controllable, then, it is sustainable. Therefore, twelve parameters, all of which are able to be regulated by government policies, were explored in this work as potential candidates for the optimal control problem. Specifically, the sensitivity analysis is used to analyze each parameter's relative impact on the system's FI. For the sensitivity analysis, the values of these parameters were increased and decreased by 5\%; then, its FI deviation from the base case was evaluated. The sensitivity analysis narrowed the list of candidate parameters from twelve to six. Half of the parameters were observed to have negligible effect on the system's FI, which indicates minimal impact on the system's sustainability. Despite not having twelve selected parameters to completely control the system, as the research of Benavides et al. (2014) would recommend, it was empirically found that these six parameters were sufficient enough to control the system for a finite amount of time (in this case, the model's simulated time duration of two hundred years). Table 1 in the Results and Discussion section summarizes the selected and non-selected parameters. Online Resource Section 2 also depicts the specifics of the methodology used for conducting the sensitivity analysis.

\subsection{Optimal Control}

Optimal control theory offers the mathematical tools necessary for steering models of engineered systems along desired pathways. It allows for the development of time-dependent strategies to optimize a system. The control problem consists of a set of mathematical equations 
describing a system involving time-dependent variables, also known as control variables, which can aid in controlling the performance of the system. For a given system, optimal control problems attempt to satisfy optimality criterion by determining a control law (Diwekar 2003). The optimality criterion is expressed as an objective function, which involves a maximization or minimization problem in terms of certain process variables.

In sustainable development, the challenge is to determine a mathematical objective that promotes the preservation of all aspects of the natural environment and human society. The objective can be formulated in two different ways: maximize the FI or minimize the variance of FI between the system under consideration and an ideal sustainable system. By maximizing FI, the system is pushed to a state that appears mathematically more sustainable. Alternatively, by minimizing FI variance, the system will be maintained in a sustainable state since the system's level of organization will strive to remain constant (Shastri and Diwekar 2006). We chose the latter approach.

As seen in Equation 4, the objective function minimizes the deviation of the system's FI from the FI of a sustainable base case (Shastri et al. 2008). The minimization function was chosen in order to follow the sustainable regime hypothesis, which states, "the system in a stable dynamic regime has a FI which is constant with time" (Shastri and Diwekar 2006). Furthermore, the maximization of FI may result in a regime change; although the system may be stable, the alternative system's characteristics may not be favorable to human existence. For this reason, we chose to minimize FI variance for the objective function. 


$$
J=\operatorname{Min}_{D V} \sum_{i=1}^{10}\left(I(i)-I_{c}(i)\right)^{2}
$$

Subject to: Model equations and bounds on decision variable DV (Kotecha et al. 2012).

Here, $\mathrm{J}$ is the objective function, $I_{c}(i)$ is the current FI, and $I(i)$ is the ideal FI for a sustainable system. The objective function can be rewritten in terms of the state and decision variables. For more information please refer to Online Resource Section 3.

We use nonlinear programming (NLP) optimization methods to solve this problem. For NLP, we need to discretize the parameter space. Therefore, the total time is divided into ten equispaced time intervals. In the six parameter optimal control problems, six decision variables represent the six policy parameters selected earlier from the sensitivity analysis as they vary over time. Each decision variable has 10 dimensions to hold the optimized values of the policy parameter for each of the 10 time intervals. Since the model runs for 200 years and there are 10 time intervals, each time interval, therefore, symbolizes 20 years. It is worth noting that the decision variable's value during each time interval remains constant for the entire course of the 20 years.

The NLP optimization problem is solved in Matlab using the constrained optimization algorithm 'fmincon'. The varying values of the policy parameters in each of the time intervals are obtained and are then plugged into the model to see the effects on the ecosystem model. The results obtained from optimization are compared with the ideal case and the projected consumption increase scenario. 
To put it all together, at each successive time step, a controlled parameter's value will change every 20 years to an optimized value, and, consequently, influence the system's FI. The parameter value is solved to satisfy the objective function to the optimal extent with the help of NLP. By satisfying the objective function during CI, the FI profile of the controlled parameter scenario will try to mimic the FI profile of the base case. Therefore, when examining CI, the controlled parameter scenario will follow a more sustainable trajectory than the uncontrolled parameter scenario.

\section{Results and Discussion}

\section{$\underline{\text { 3.1 Sensitivity Analysis }}$}

Below in Table 1, you will find a summary of the selected and non-selected parameter from the sensitivity analysis. Six of the twelve parameters were ultimately selected for optimal control. It is useful to be familiar the real world meanings, and hence the policy implications, associated with the selected parameters. The selected parameters come from all three categories of variables being explored in the model: regulatory, economic, and technological.

Table 1 Candidate policy options for the sensitivity analysis

\begin{tabular}{|c|c|c|c|c|c|}
\hline Category & Name & Parameter & $\begin{array}{l}\text { Mass-Flo } \\
\mathrm{w}\end{array}$ & Meaning & Selected? \\
\hline \multirow{2}{*}{$\begin{array}{l}\text { Regulatory } \\
\text { Variables }\end{array}$} & Discharge Fee & $\mathrm{d}_{\text {fee }}$ & $\mathrm{IS} \rightarrow \mathrm{IRP}$ & $\begin{array}{l}\text { Discharge fee imposed by } \\
\text { government to the Industry } \\
\text { sector for waste disposal. }\end{array}$ & Yes \\
\hline & $\begin{array}{l}\text { Energy } \\
\text { Production Fee }\end{array}$ & $\mathrm{d}_{\mathrm{EE}}^{\text {fee }}$ & $\mathrm{EP} \rightarrow \mathrm{IRP}$ & $\begin{array}{l}\text { Discharge fee imposed by } \\
\text { government to the energy } \\
\text { producers. }\end{array}$ & No \\
\hline $\begin{array}{l}\text { Economic } \\
\text { Variables }\end{array}$ & $\begin{array}{l}\text { Plant } \\
\text { Consumption }\end{array}$ & $\mathrm{k}_{\mathrm{P} 1}$ & $\mathrm{P} 1 \rightarrow \mathrm{HH}$ & $\begin{array}{l}\text { Parameter relating the price of } \\
\mathrm{P} 1 \text { to the demand of } \mathrm{P} 1 \text { by } \\
\text { human households }\end{array}$ & Yes \\
\hline
\end{tabular}




\begin{tabular}{|c|c|c|c|c|c|}
\hline & $\begin{array}{l}\text { Animal } \\
\text { Consumption }\end{array}$ & $1_{\mathrm{H} 1}$ & $\mathrm{H} 1 \rightarrow \mathrm{HH}$ & $\begin{array}{l}\text { Parameter relating the price of } \\
\mathrm{H} 1 \text { to the demand of } \mathrm{H} 1 \text { by } \\
\text { human households }\end{array}$ & Yes \\
\hline & Agricultural Fee & $\mathrm{F}_{\mathrm{P} 1 \mathrm{H} 1}$ & $\mathrm{P} 1 \rightarrow \mathrm{H} 1$ & $\begin{array}{l}\text { Parameter relating the price of } \\
\mathrm{P} 1 \text { and the demand of } \mathrm{P} 1 \text { by } \mathrm{H} 1\end{array}$ & No \\
\hline & $\begin{array}{l}\text { Plant Material } \\
\text { Fee }\end{array}$ & $\mathrm{S}_{\mathrm{P} I I S}$ & $\mathrm{P} 1 \rightarrow \mathrm{IS}$ & $\begin{array}{l}\text { Parameter relating the price of } \\
\text { P1 to the demand of IS }\end{array}$ & No \\
\hline & $\begin{array}{l}\text { Industrial Energy } \\
\text { Consumption }\end{array}$ & $\mathrm{S}_{\text {EEIS }}$ & $\mathrm{EP} \rightarrow \mathrm{IS}$ & $\begin{array}{l}\text { Parameter relating the price of } \\
\text { energy to the demand of IS }\end{array}$ & No \\
\hline & $\begin{array}{l}\text { Household } \\
\text { Energy } \\
\text { Consumption }\end{array}$ & $\mathrm{O}_{\mathrm{EE}}$ & $\mathrm{EP} \rightarrow \mathrm{HH}$ & $\begin{array}{l}\text { Parameter relating the price of } \\
\text { energy to the demand of energy } \\
\text { by Human household }\end{array}$ & No \\
\hline & $\begin{array}{l}\text { Household } \\
\text { Biofuel } \\
\text { Consumption } \\
\end{array}$ & $\mathrm{K}_{\mathrm{EE}}$ & $\mathrm{P} 1 \rightarrow \mathrm{EP}$ & $\begin{array}{l}\text { Parameter relating the price of } \\
\text { P1 to the demand of energy by } \\
\text { Human household }\end{array}$ & No \\
\hline & Theta & $\theta_{\mathrm{P} 1}$ & $\mathrm{P} 1 \rightarrow \mathrm{IS}$ & $\begin{array}{l}\text { Amount of } \mathrm{P} 1 \text { required to } \\
\text { produce a unit of industrial } \\
\text { product IS }\end{array}$ & Yes \\
\hline $\begin{array}{l}\text { Technologic } \\
\text { variables }\end{array}$ & Khat & $\hat{k}$ & $\mathrm{P} 2 \rightarrow \mathrm{H} 1$ & $\begin{array}{l}\text { Constant value specified by the } \\
\text { government. Represents the } \\
\text { grazing of } \mathrm{P} 2 \text { by } \mathrm{H} 1 \text {. }\end{array}$ & Yes \\
\hline & $\begin{array}{l}\text { Biomass to } \\
\text { Biofuel } \\
\text { Conversion Rate }\end{array}$ & $\lambda_{\text {biom }}$ & $\mathrm{P} 1 \rightarrow \mathrm{EP}$ & $\begin{array}{l}\text { Amount of biomass (P1) needed } \\
\text { to produce a unit of biofuel }\end{array}$ & Yes \\
\hline
\end{tabular}

The sensitivity analysis of each parameters can give a basic intuition of how various compartments in the system react to changes in certain parameter values. For example, Figure 2 shows how the sensitivity analysis of the plant consumption parameter, $\mathrm{k}_{\mathrm{P} 1 \text {, affects certain }}$ compartments (e.g. P1, H1, and C1). As seen in Table 1, the parameter $\mathrm{k}_{\mathrm{P} 1}$ relates the price of P1 (primary producer) to the demand of $\mathrm{P} 1$ by $\mathrm{HH}$ (human households). Therefore, increasing $\mathrm{k}_{\mathrm{P} 1}$ makes $\mathrm{P} 1$ more expensive for $\mathrm{HH}$, which reduces $\mathrm{HH}$ demand for $\mathrm{P} 1$ and decelerates the depletion of $\mathrm{P} 1$. This is reflected in Figure 2A since the green profile, signifying a 5\% increase in $\mathrm{k}_{\mathrm{P} 1}$, has a slowed depletion relative to the blue profile, the base case. The green profiles in $2 \mathrm{~B}$ and 2C green profiles indicate that herbivores and carnivores species (i.e. $\mathrm{H} 1$ and $\mathrm{C} 1$, respectively) also deplete at a slower rate relative to the base case; the slightly increased lifespan for these 
species can be attributed to a larger food source of P1 since P1 is not being as rapidly depleted through human consumption. However, Figure 2D's green profile shows how human per capita mass drops, indicating less P1 was available as a food source for human beings due to price increases.
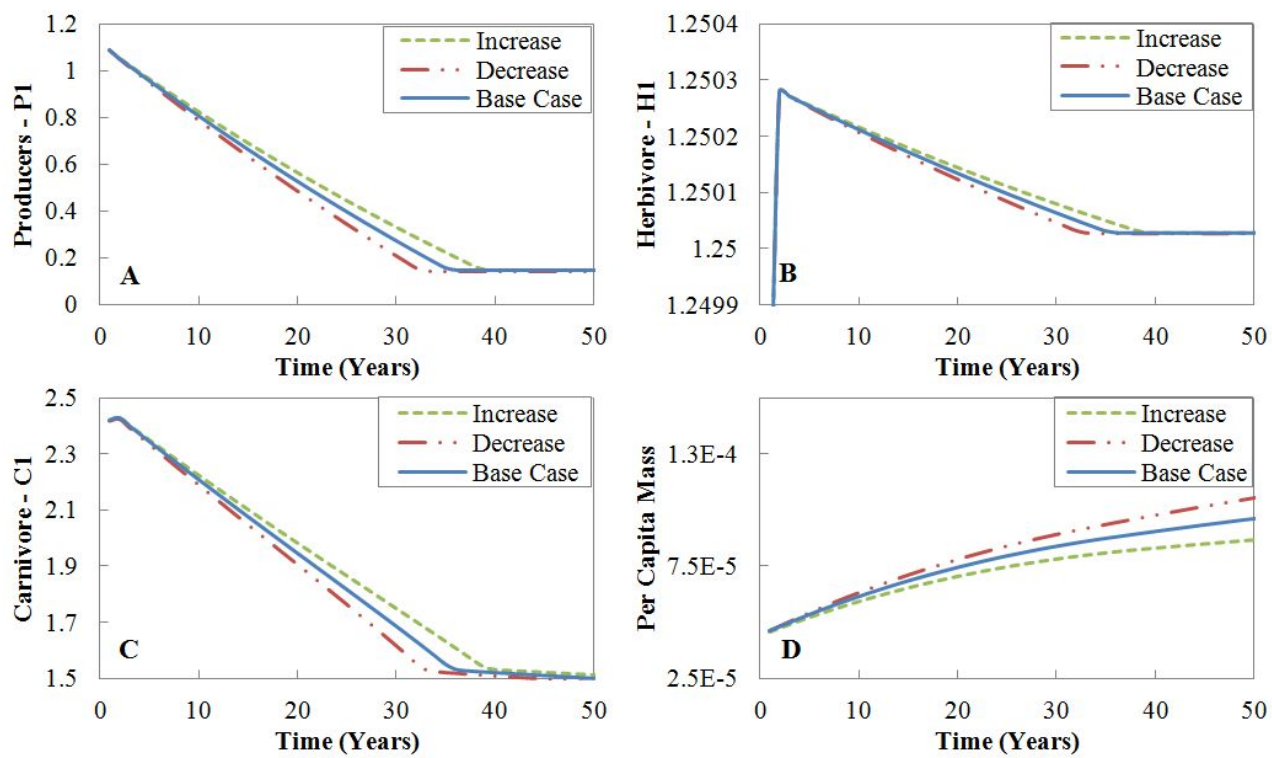

Fig. 2 Sensitivity analysis results for plant consumption $\left(k_{\mathrm{P} 1}\right)$ without consumption increase. $\mathrm{k}_{\mathrm{P} 1}$ is increased and decreased by $5 \%$ to observe changes in $\mathrm{P} 1, \mathrm{H} 1, \mathrm{C} 1$, and per capita mass. The base case $\mathrm{k}_{\mathrm{P} 1}$ value is used as a standard of comparison

Looking to the real world, the conclusions derived from the sensitivity analysis provide keen insights about the relationship between human appropriation of net primary productivity (HANPP) and biodiversity. Our planet's primary producers generate a finite amount of biomass annually. This biomass provides humans with food, fiber, and fuel, but, the same biomass is a vital dietary resource for other animals and microorganisms. HANPP tells us how much of the planet's capacity to produce biomass is occupied by humans, serving as a useful metric on human alteration of the biosphere. During the last century, HANPP has doubled from around $13 \%$ to $25 \%$. Furthermore, estimates predict that HANPP will raise to $44 \%$ globally by 2050 due 
to the increased usage of biofuels (Krausmann et al. 2013). The literature also indicates evidence that increases in HANPP correlate to decreases in biodiversity (Harbel et al. 2005; Rodríguez-Labajos and Martínez-Alier 2013). The reasoning matches the conclusions from the sensitivity analysis of the plant consumption parameter: if humans consume more biomass, then there is less biomass available to other species (e.g. herbivores and carnivores). To support this, by looking to the red profile in Figure 2 and examining the decrease in $\mathrm{k}_{\mathrm{P} 1}$, one can see the increase in per capita mass of humans is correlated to the depletion $\mathrm{P} 1, \mathrm{H} 1$, and $\mathrm{C} 1$.

While the sensitivity analysis for other parameters can be found in Online Resource 2, there are still a few key findings worth mentioning. First, the sensitivity analysis for the animal consumption parameter $\left(l_{\mathrm{H} 1}\right)$ suggests that increased consumption of herbivores will adversely affect carnivore populations while leaving primary producer populations unaffected. Furthermore, the sensitivity analysis for the biomass to biofuel conversion rate parameter $\left(\lambda_{\text {biom }}\right)$ reveals that, when it comes to humans deciding how to utilize biomass, there is an inherent tradeoff between meeting human food and energy needs; basically, since the amount of biomass generated by primary producers in limited, allocating biomass for biofuel comes at the expense of biomass available for food, and vice versa. Applying this trend in the model to the real world provides insight on how U.S. subsidies for the production of corn ethanol may be responsible for cost increases in international food prices (Waage 2008). These discussion above reveals the type of qualitative conclusions about ecological systems a sensitivity analysis can yield.

\subsection{Single Variable Optimal Control}


The purpose for conducting single variable optimal control is to confirm the effectiveness of each parameter from the sensitivity analysis as a decision variable in control problems. Each of the six selected parameters from Table 1 were independently controlled and evaluated. To document an example of this process, this paper includes the results from controlling the plant consumption parameter (i.e. $\mathrm{k}_{\mathrm{P} 1}$ ). Also, single variable optimal control is meant to serve as a basis for comparison when evaluating the impact of multivariable optimal control on sustainability.

Figure $3 \mathrm{E}$ compares the controlled and uncontrolled values of $\mathrm{k}_{\mathrm{P} 1}$. The optimal control results suggest increasing $\mathrm{k}_{\mathrm{P} 1}$ for the first eighty years. Increasing $\mathrm{k}_{\mathrm{P} 1}$ would increase the cost for P1 by $\mathrm{HH}$; therefore, humans will purchase less biomass. In the real world, this could be implemented through a tax on the purchasing on biomass. The model predicts that this policy strategy would decelerates the depletion of P1, H1, and C1, as predicted in Figure 3A, Figure 3B, and Figure 3C, respectively. To explain this, since P1 is more expensive for the first eighty years, humans will consume fewer primary producers during this time; the slightly larger plant population in the controlled scenario relative to the base case will act as an increased food source capable of supporting more herbivores and carnivores relative to the base case. Therefore, the slowed rate of depletion of $\mathrm{P} 1$ is responsible for the slowed rate of depletion of $\mathrm{H} 1$ and $\mathrm{C} 1$. After 80 years, the $\mathrm{k}_{\mathrm{P} 1}$ parameter reverts back to its default levels; the real-world policy analog would be the expiration of the biomass tax mentioned earlier. Figure 3D shows the FI for the 3 cases. The controlled parameter scenario has less deviance from the base case compared to the uncontrolled parameter scenario during consumption increase. Figure 3D, however, indicates 
that $\mathrm{k}_{\mathrm{P} 1}$ alone does not significantly increase the sustainability of the system since the FI of the controlled scenario still begins its decreases to zero after the $50^{\text {th }}$ year, just like the uncontrolled scenario. Regardless of the improvements due to the controlling of the $\mathrm{k}_{\mathrm{P} 1}$ parameter, the system still goes extinct while running a consumption increase scenario. This motivates us to explore multivariable control.
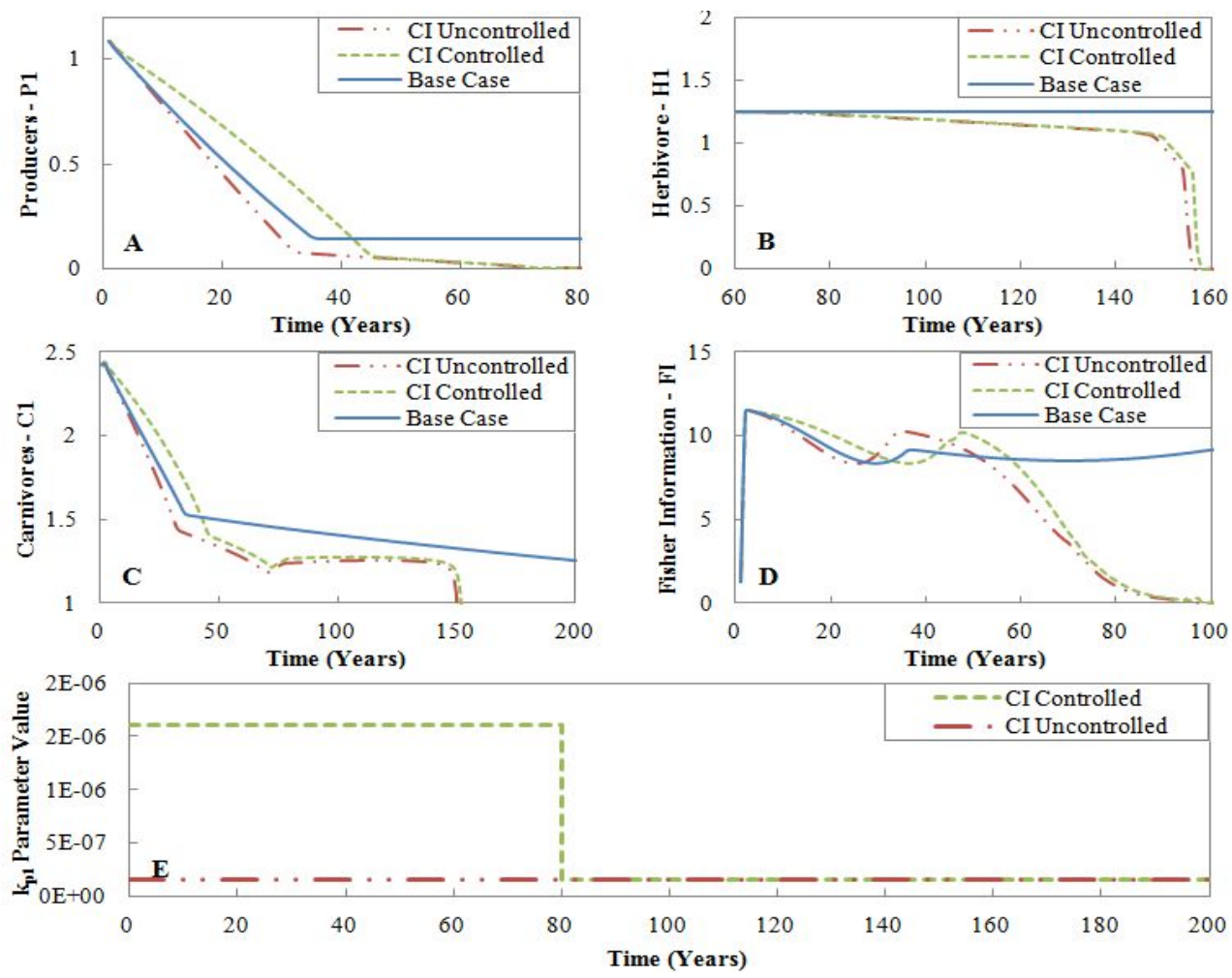

Fig. 3 Effects of controlled and uncontrolled plant consumption $\left(k_{\mathrm{P} 1}\right)$ on P1, H1, C1, and FI. CI stands for consumption increase. The controlled parameter scenario (green profile) is aiming to emulate the sustainable base case (blue profile) and avoid extinction, a path taken by the uncontrolled parameter scenario (red profile). Also, the control profile for $\mathrm{k}_{\mathrm{P} 1}$ is included to show how its value varies with time relative to the constant uncontrolled parameter values.

\section{$\underline{3.3 \text { Multivariable Optimal Control }}$}

In this section, we first present the results of the simultaneous control of three parameters: $\mathrm{k}_{\mathrm{P} 1}, 1_{\mathrm{H} 1}$, and $\lambda_{\text {biom }}$. As seen in Figures $4 \mathrm{~A}, 4 \mathrm{~B}$, and $4 \mathrm{C}$, there is a slight improvement 
from single variable optimal control since the lifespan of $\mathrm{P} 1, \mathrm{H} 1$, and $\mathrm{C} 1$ all increase by approximately 5 years. Figures $5 \mathrm{~A}$ to $5 \mathrm{C}$ depict potential policy values for twenty year intervals if the government were to simultaneously implement and coordinate the three regulatory options represented by the three parameters. For example, looking to Figure 5 to determine a general policy strategy for the first twenty years, one may conclude to implement a tax increase for biomass (correlates to the increase in $\mathrm{k}_{\mathrm{P} 1}$ ), slight tax increase for the purchasing of livestock (correlates to the minor increase in $1_{\mathrm{H} 1}$ ), and a relaxing of the standards which dictate the conversion rate of biomass to biofuel (correlates to the decrease in $\lambda_{\text {biom }}$ ). Still, as seen in Figure $4 \mathrm{D}$, controlling three parameters is not enough to ensure sustainability during the consumption increase scenario; the green controlled profile still hits zero within a hundred years, which is only half of the model's two hundred year duration. This realization urges us to explore whether the optimization of six parameters would give enough control over the system to guide it towards sustainability for the model's full duration.
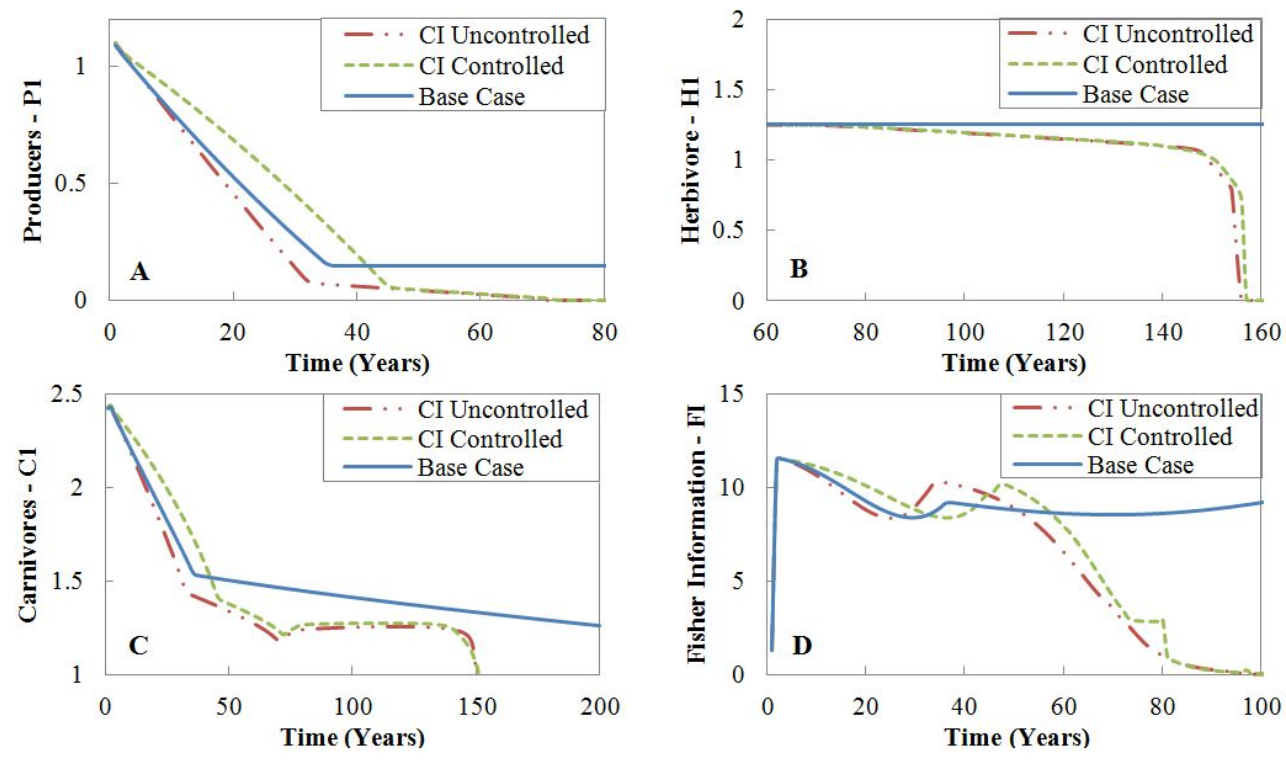
Fig. 4 Three parameter multivariable optimal control. Graphs A to D depict the effects of three parameter optimal control on P1, H1, C1, and FI. In the legend, CI stands for Consumption Increase. The controlled parameter scenario (green profile) is aiming to emulate the sustainable base case (blue profile) and avoid extinction, a path taken in the uncontrolled parameter scenario (red profile)
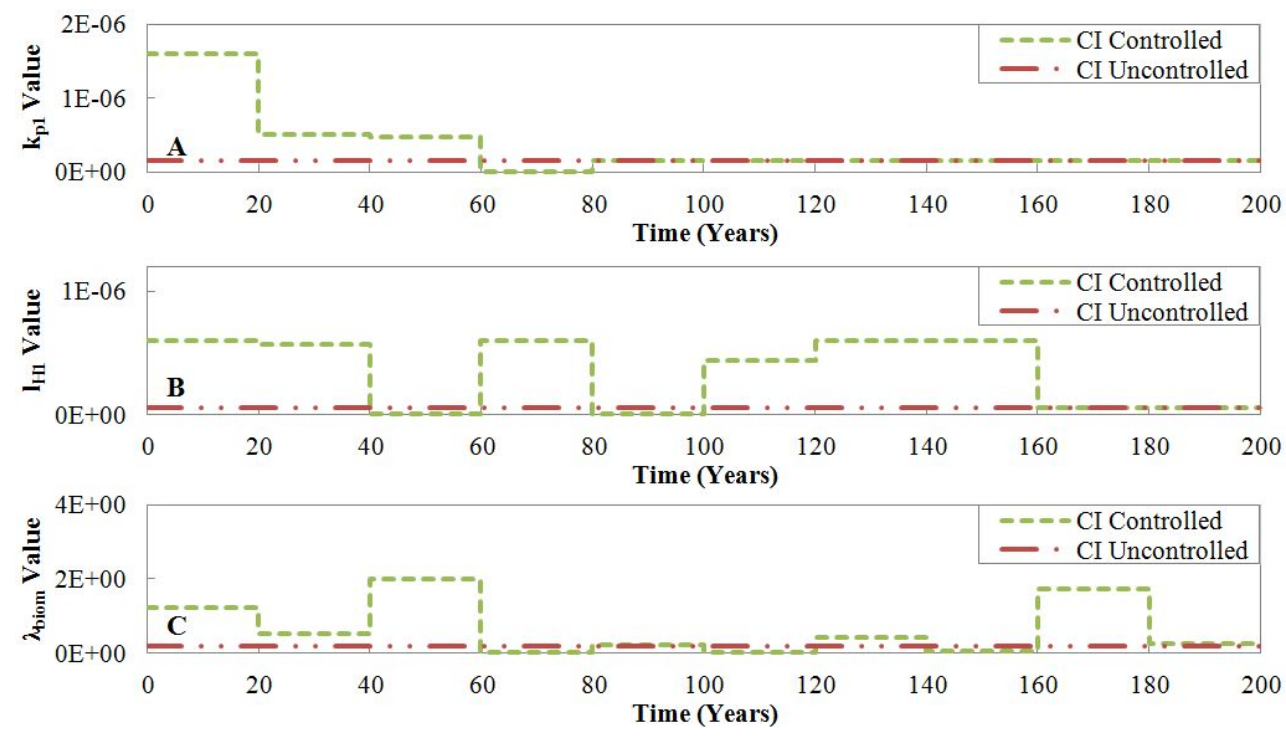

Fig. 5 Three parameter optimal control profiles. Graphs A-C show how the three controlled parameters vary with time relative to the constant uncontrolled parameter values.

Figures $6 \mathrm{~A}$ to $6 \mathrm{D}$ present the results of dynamic optimization using all the six control variables. Only the most influencing compartments are presented whereas others are reported in Online Resource Section 4. Considering Figure 6D, it can be observed how the green profile is deviating from the red profile and better matching the blue profile, reflecting the extended lifespan of each compartment in the system (see Figure 6A to 6C). This indicates that optimal control helps the model to better match the behavior of the base case. Figure 7 graphs the value of the objective function, the accumulated FI variation from the base case, for the uncontrolled and controlled scenarios. By comparing the green profile to the red profile, one can see that the accumulation of FI variance was successfully minimized, proving the objective function was 
satisfied. Interestingly, in Figure 7, around year 70, the objective function value for the uncontrolled case dramatically began increasing since, according to Figure 6D, the model's FI approached zero, resulting in maximum deviation from the base case. Putting together all the conclusions from Figure 6 and Figure 7, one can see that minimizing FI variance by controlling six parameters sustained all the model compartments for at least 200 years despite increased resource consumption by humans - a key breakthrough. While one parameter and three parameter optimal control may not have been able to guide sustainable development for 200 years, six parameters optimal control finally managed to achieve to do so, a crucial extension of previous research on this model.
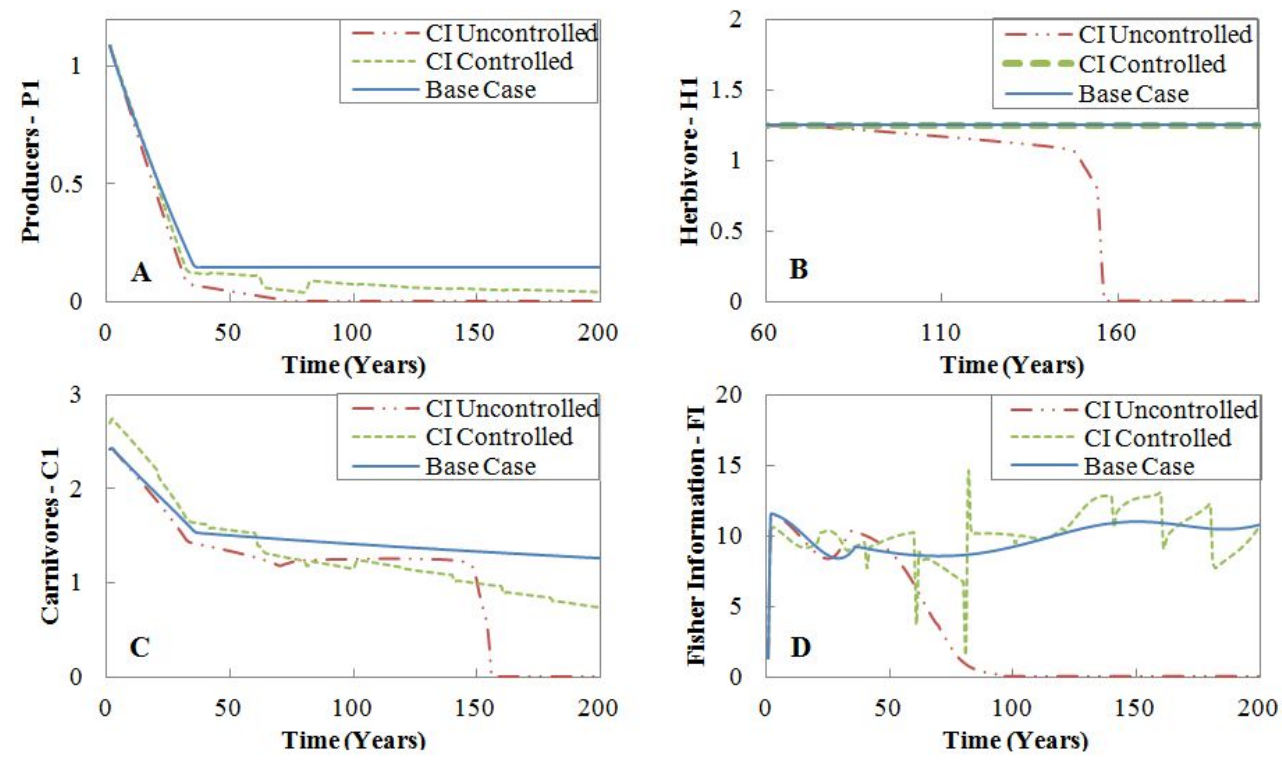

Fig. 6 Six parameter multivariable optimal control profiles. Graphs A to D depict the effects of multivariable optimal control on P1, H1, C1, and FI. In the legend, CI stands for Consumption Increase. The controlled parameter scenario (green profile) aims to emulate the sustainable base case (blue profile) and avoid extinction, a path taken by the uncontrolled parameter scenario (red profile) 


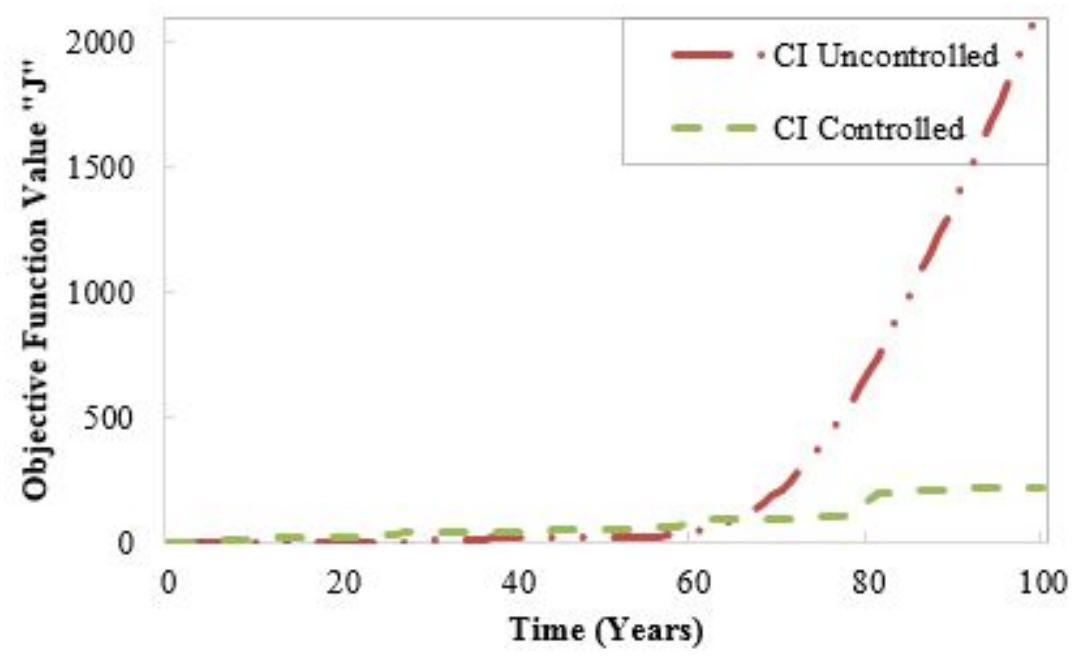

Fig. 7 Objective function profile for six parameter multivariable optimal control. The objective function increases as deviation from the base case FI value is accumulated. By comparing the green profile to the red profile, it is seen that controlling the model's six parameters significantly slows the accumulation of FI deviation from the base case.

The implementation of the control strategy of the six parameters is illustrated in Figure 8. In this figure, we can observe the fluctuation of each parameter every 20 years, which can represent a 20 year plan that the government can use. It has not escaped our notice that the parameter values change drastically over short periods of time between the time steps, which may be seen as unrealistic in a real-world policy context. However, we found that gradual parameter changes does this idea, as a goal for future work, the model can be altered to facilitate a smooth change in parameter values over greater amounts of time but we include additional control parameters than the six we have chosen. This will signifying the gradual adoption and implementation of government standards and legislation. 

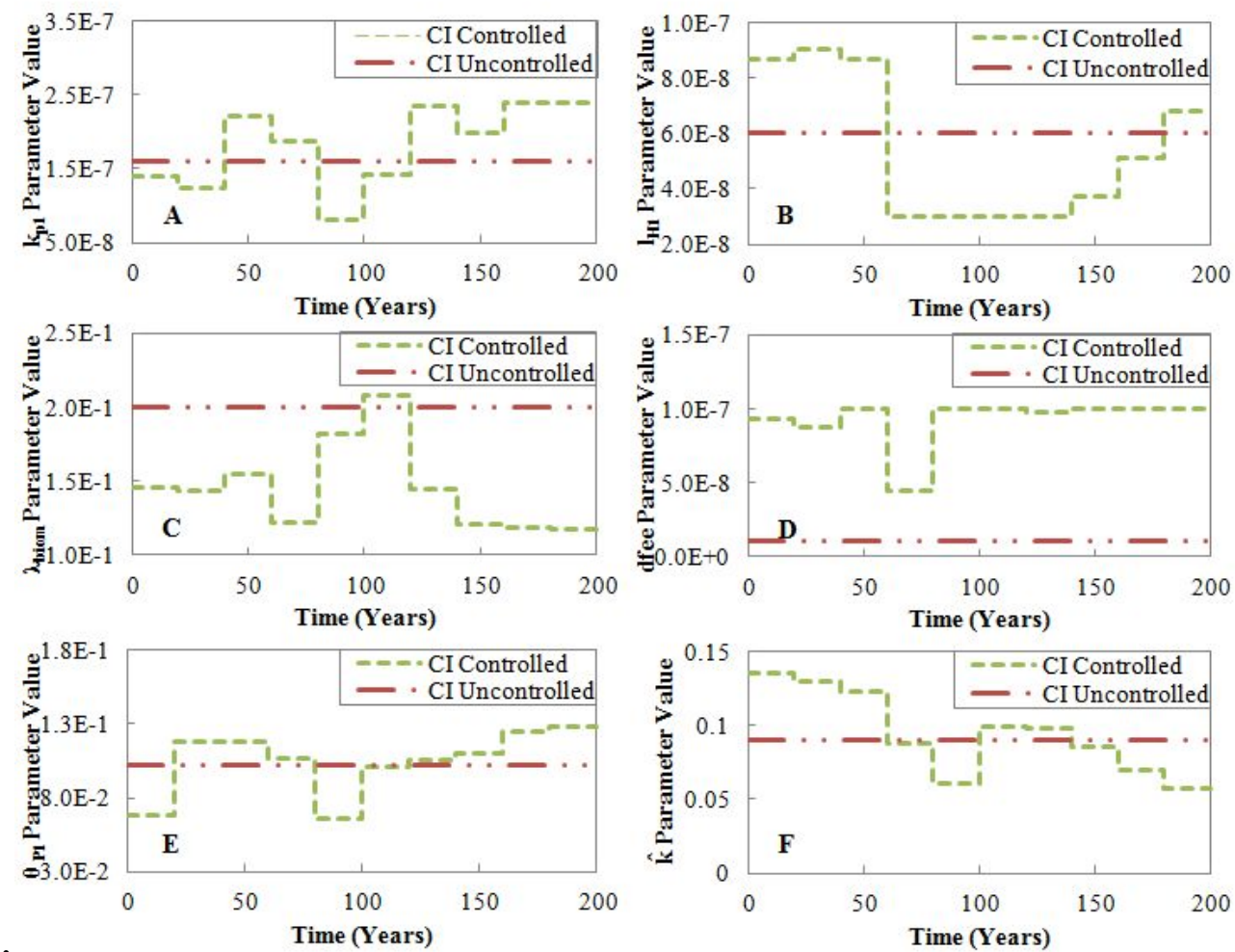

Fig. 8 Six parameter optimal control profiles. Graphs A-F show a comparison of the control profiles with the uncontrolled parameters and how their values vary over time

Comparing Figure 3D, 4D, and 6D, it is evident that having control over a greater number of decision variables (policy options) allows us to better control the FI, thus, the sustainability of the system. Additionally, we can conclude that multivariable optimal control is preferable over single variable optimal control. This reinforces the idea that there is not a single magical solution to the world's sustainability needs. Rather, a combination of regulatory strategies implemented to various degrees would be most effective.

\section{Conclusion}

In this work, we used optimal control techniques to guide a mathematical model of the planet away from extinction and towards a path of sustainable development for at least 200 
years. We met original goals; none of the eight ecological compartments (P1, P2, P3, H1, H2, $\mathrm{H} 3, \mathrm{C} 1$, and $\mathrm{C} 2$ ) went extinct and growing resource demands from human society were met. This was a vital extension to previous work on this model since this is the first time multivariable optimal control has been successfully applied to achieve such long term sustainable development. We achieved this by controlling real-world policy analogs in the model: industrial waste discharge fees, biomass fees, animal fees, industrial efficiency regulation, grazing fees, and biomass to biofuel conversion rate standards. By grounding this work in real-world policy options within regulatory reach, we demonstrated how the strategic implementation of policies may have a significant impact on sustainability in practicality.

Also, we examined how the model reacted to manipulating different policy options and yielded both qualitative and quantitative conclusions relevant to sustainable ecosystem management. For example, the sensitivity analysis yielded insights into real-world policy challenges such as the trade-off between using biomass for food and fuel and the inverse relationship between HANPP and biodiversity. This work also showed how there is a critical level of control - a "tipping point" per se - necessary for guiding a complex system, such as the environment, along a path of sustainable development. While efforts to control one and three parameters failed to guide the system towards sustainable development, simultaneously controlling and optimizing six policy parameters managed to ensure system sustainability for at least 200 years. Then, models like the only developed in this work can be used by policy makers to figure out the necessary amount of system control needed for sustainable development. Ultimately, integrating sustainable ecosystem management with multivariable optimal control 
techniques and mathematical modeling can be useful for defining policy approaches that maintain the integrity of the environment and satisfy consumption demands.

Still, even this model is not perfect, which is why there is room for future work. As mentioned earlier in section 3.3, the model should be refined to transition between controlled parameter values gradually to reflect the time lag associated with the adoption of new government regulations. Another goal for the future is to incorporate new fuel sources such as shale gas and algae in order to further understand the role of energy production in determining decisions regarding sustainability.

\section{Acknowledgements}

This work was made possible and supported by VRI-CUSTOM (Vishwamitra Research Institute

- Center for Uncertain Systems: Tools for Optimization \& Management).

\section{References}

Benavides P, Diwekar U, Cabezas H (2014) Controllability of Complex Networks for Sustainable System Dynamics. Submitted to J of Complex Netw

Brock W, Xepapadeas A (2010) Pattern formation, spatial externalities and regulation in coupled economic - ecological systems. J Environ Econ Manag 59:149-164. doi: 10.1016/j.jeem.2009.07.003

Brundtland GH (1987) Our Common Future: Report of the World Commission on Environment and Development. Oxford University Press. http://www.un-documents.net/our-common- 
future.pdf

Cabezas H, Fath BD (2002) Towards a theory of sustainable systems. Fluid Phase Equilibria 194:3-14. doi: 10.1016/S0378-3812(01)00677-X

Chakraborty K, Das S, Kar TK (2011) Optimal Control of Effort of a Stage Structured Preypredator Fishery Model with Harvesting. Nonlinear Anal Real World Appl 12:3452-3467. doi: 10.1016/j.nonrwa.2011.06.007

Diwekar, U (2003) Introduction to Applied Optimization. Norwell, MA

Chang DS, Yeh LT, Liu W (2014) Incorporating the carbon footprint to measure industry context and energy consumption effect on environmental performance of business operations. Clean Technol Environ Policy. doi: 10.1007/s10098-014-0785-9.

Haberl H, Plutzar, C, Erb KH, Gaube V, Pollheimer M, Schulz NB (2005) Human appropriation of net primary production as determinant of avifauna diversity in Austria. Agric Ecosyst Environ 100:119-131. doi: 10.1016/j.agee.2005.03.009

Frieden BR (1998) Physics from Fisher information: A Unification. Cambridge, UK

Kotecha P, Diwekar U, Cabezas H (2012) Model-based Approach to Study the Impact of Biofuels on the Sustainability of an Ecological System. Clean Technol Environ Policy 15:21-33. doi: DOI 10.1007/s10098-012-0491-4

Krausmann F, Erba KH, Gingricha S, Haberla H, Bondeaub A, Gaubea V, Lauka C, Plutzara C, Searchingerd TD (2012) Global human appropriation of net primary production doubled in the 20th century. Proc Natl Acad Sci. 110:10324-10329. doi:

$10.1073 /$ pnas. 1211349110 
Mäler K, Xepapadeas A, Zeeuw AD (2003) The Economics of Shallow Lakes. Environ Recour Econ 26:603-624. doi: 10.1023/B:EARE.000000735

Meadows DH, Meadows DL, Randers J (1992) Beyond the Limits: Confronting Global Collapse, Envisioning a Sustainable Future. Post Mills, VT

Menshutkin VV, Rukhovets LA, Filatov NN (2014) Ecosystem Modeling of Freshwater Lakes (Review): 2. Models of Freshwater Lake's Ecosystem. Water Resourc 41: 32-45. doi: $10.1134 / \mathrm{S} 0097807814010084$

Rodríguez-Labajos B, Martínez-Alier J (2013) The Economics of Ecosystems and Biodiversity: Recent Instances for Debate. Conserv Society 11:326-342. doi: $10.4103 / 0972-4923.125744$

Shastri Y, Diwekar U (2006) Sustainable ecosystem management using optimal control theory: Part 1 (deterministic systems). $\mathrm{J}$ of Theor Biol 24:506-521. doi: 10.1016/j.jtbi.2005.12.014

Shastri Y, Diwekar U, Cabezas H (2008) Williamson, J. Is Sustainability Achievable? Exploring the Limits of Sustainability with Model Systems. Environ Sci Technol 42:6710-6716. doi: $10.1021 / \mathrm{es} 800661 \mathrm{x}$

Sohngen B, Mendelsohn R (2003) An Optimal Control Model of Forest Carbon Sequestration. Am J Agr Econ 85:448-457. doi: 10.1111/1467-8276.00133

Waage E (2008) U.S. Energy Policy Response to International Food Prices: The Costs and Effects of Corn Ethanol Production. Politics and Policy 36:792-804. doi: 10.1111/j.17471346.2008.00135.x 
Whitmore HW, Pawlowski CW, Cabezas H (2006) Integration of an Economy under Imperfect Competition with a Twelve-Cell Ecological Model. United States Environmental Protection Agency. http://nepis.epa.gov/Adobe/PDF/P100778R.pdf 